\title{
PERIPARTUM CARDIOMYOPATHY:AN OVERVIEW
}

\author{
Wan Azman WA and Haizal HK \\ The Division of Cardiology, Faculty of Medicine, University of Malaya, 50603 Kuala Lumpur
}

\begin{abstract}
Peripartum cardiomyopathy (PPCM) is a life-threatening cardiomyopathy of an unknown cause that occurs in the peripartum period in previously healthy women and this article discusses the challenges that lie in diagnosing and managing this rare yet lethal disease. (JUMMEC 2003-2005; 8: 18-22)
\end{abstract}

KEYWORDS: Peripartum, cardiomyopathy, pregnancy, cardiac failure

\section{Definition}

Peripartum cardiomyopathy (PPCM) is defined on the basis of four criteria, adapted from the work by Demakis, et al (I) which are (a) the development of cardiac failure during pregnancy or within five months of delivery, (b) the absence of a determinable cause for cardiac failure, (c) the possibility of occurrence in patients with coincidental heart disease, and (d) the demonstration of impairment of left ventricular systolic function. The peripartum period is as defined to exclude preexisting causes of cardiomyopathy that may be exacerbated by pregnancy rather than arising as a result of pregnancy.

\section{Incidence}

The actual incidence of PPCM is not known because population-based estimates are not available and there may be a lot of undiagnosed cases. The reported incidence ranges from one per 1,300 to one per 15,000 with a higher incidence in Africa (2). However, the currently accepted incidence is approximately one per 3,000 to one per 4,000 live births (3).

\section{Predisposing Factors}

Classical risk factors for PPCM include multiparity, advanced maternal age, multifoetal pregnancy, preeclampsia and gestational hypertension, and AfricanAmerican race (I).

\section{Aetiology}

The reported incidence of PPCM is higher than the incidence of idiopathic cardiomyopathy. As such, it is thought to be a distinct entity, rather than a clinically silent underlying cardiomyopathy unmasked by the haemodynamic stresses of pregnancy (4).

A number of possible causes have been proposed for PPCM, including myocarditis, abnormal immune response to pregnancy, maladaptive response to the haemodynamic stresses of pregnancy, stress-activated cytokines, and prolonged tocolysis. In addition, there have been a few reports of familial PPCM (5-7), raising the possibility that some cases of PPCM are actually familial dilated cardiomyopathy unmasked by pregnancy. Some of the key hypotheses are discussed below.

\section{Myocarditis}

Myocarditis has been shown by endomyocardial biopsy in PPCM (8) and its incidence can be as high as $76 \%$ of cases (9). The absent or muted immune response during pregnancy may allow for unchecked viral replication and thus a greater likelihood of myocarditis in the setting of a viral infection. Studies in pregnant mice demonstrated enhanced susceptibility to viral myocarditis due to coxsackie viruses and echoviruses (10). The hypothesis is that if viral genetic products are evident, the postviral immune response of the patient may have been inappropriately targeted against otherwise cryptic cardiac tissue proteins, leading to ventricular dysfunction.

\section{Correspondence:}

Dr Haizal Haron Kamar

Faculty of Medicine,

University of Malaya,

50603 Kuala Lumpur.

Tel: 603-7950 2429

Email: haizal@um.edu.my 


\section{Abnormal immune response to pregnancy}

The occurrence of chimerism of the haematopoietic lineage cells from the foetus to the mother during pregnancy have been reported (II-I2). If these cells, which are weakly immunogenic, escape into the mother's circulation and reside in cardiac tissue during the immunosuppressed pregnant state, then following postpartum recovery of immune competence, they are recognized as nonself by the maternal immune system and a pathologic autoimmune response may be triggered leading to myocarditis.

\section{Response to haemodynamic stresses of pregnancy}

During pregnancy, blood volume (preload) and cardiac output increase and afterload decreases. In addition, the left ventricle remodels in response to the haemodynamics of pregnancy, resulting in transient hypertrophy. The research (I3) and other studies (14) have shown a reversible decrease in left ventricular systolic function in the second and third trimesters that persisted into the early postpartum period, but returned to baseline shortly thereafter. It is possible that PPCM may be due, in part, to an exaggeration of this decrease in systolic function.

\section{Other aetiologic factors}

There are other causes for PPCM that merit further study such as: (a) prolonged tocolysis (15), (b) stressactivated proinflammatory cytokines such as tumor necrosis factor-alpha or interleukin-6 that have been implicated in the pathophysiology of idiopathic dilated cardiomyopathy (16), and (c) abnormalities of relaxin, primarily an ovarian hormone produced during pregnancy, recently found in cardiac atria, shown to have positive inotropic and chronotropic properties (17) and potentially involved in excessive relaxation of the cardiac skeleton.

\section{Clinical Presentation}

PPCM can present in a number of different ways. Some of the known clinical presentations are arrhythmias (18), thromboembolic events $(1,19)$ and cardiac arrest during anaesthesia (20). However, by far the commonest symptoms and signs are those of congestive cardiac failure, such as dyspnoea, orthopnoea, and paroxysmal nocturnal dyspnoea (2I-22).

This presents a challenge because many women in the last month of a normal pregnancy experience dyspnoea, fatigue, and pedal oedema, symptoms identical to early congestive heart failure. PPCM may, therefore, go unrecognized, leading to under- estimation of incidence. There are no specific criteria for differentiating subtle symptoms of heart failure from normal late pregnancy, so it is important that a high index of suspicion be maintained to identify the rare case of PPCM.

\section{Management}

A few issues need to be considered when managing PPCM cases. Firstly, is the stage of PPCM, that is, prepartum versus postpartum period. Secondly, in the prepartum period, management also takes into account the welfare of the foetus. Thirdly, is the mode of cardiac failure presentation, which is either acute (unstable) or chronic (stable).

In the prepartum period, the principle issue is the timing of delivery. Many factors must be taken into consideration including the success of medical therapy, perception of cardiac stress and anaesthesia risk. In selective cases, conservative management with medical therapy may be appropriate. If pulmonary maturity on amniocentesis can be demonstrated, prompt delivery of the patient would appear to be the best mode of therapy. In patients with unstable maternal haemodynamics, the maternal and secondary foetal risks demand prompt delivery as part of the patient's treatment protocol.

The postpartum management is similar to that of other non-ischaemic dilated cardiomyopathies, which is preload and afterload reduction, and increase inotropy.

\section{Management of stable PPCM patient}

\section{(a) Non-pharmaceutical therapy}

These include low sodium diet (less than $4 \mathrm{gm} \mathrm{a}$ day), fluid intake restriction and modest daily exercise (e.g. walking).

\section{(b) Pharmaceutical therapy}

The cornerstone of optimal outpatient oral pharmacologic therapy for cardiomyopathy begins with afterload reduction with the use of angiotensinconverting enzyme inhibitors (ACEI) or angiotensin II receptor blockers (ARB) (23-25). Unfortunately, pregnancy is a contraindication to the use of ACEI and ARB. In this instance, the use of hydralazine and nitroglycerine can be safely used in pregnancy to provide the much needed afterload reduction (26).

Preload reduction can be achieved with diuretic and low dose oral nitrates. In pregnancy, diuretics must be used with caution to avoid dehydration. 
Oral inotropic therapy can be provided by digoxin (27). The deleterious effect of excessive sympathetic nervous system may be blocked and reversed with b-blockers (28-30).

Calcium channel blockers have negative inotropic properties that may make them unacceptable for use in this situation but amlodipine, a dihydropyridine calcium channel blocker, has been shown to improve survival in non-ischaemic cardiomyopathy patients $(3 \mathrm{I})$ and may have a role in management of PPCM.

A suggested treatment regimen for stable PPCM is outlined in Table I.

\section{Management of unstable PPCM patient}

In acutely ill or highly symptomatic patients, intravenous preload- and afterload-reducing agents (e.g. nitroglycerin) and/or inotropic agents (e.g. dopamine and dobutamine) should be considered. These agents can be used in pregnancy if medically indicated.

Table I. Suggested treatment plan in stable peripartum cardiomyopathy

I. Start diuretic therapy (e.g. frusemide $40 \mathrm{mg}$ od) to control symptoms due to volume excess. Use with caution in prepartum patients.

2. In postpartum patients, institute ACEI and titrate up to the maximum tolerated dose. In prepartum patients, use hydralazine and isosorbide dinitrate combination therapy to lower the systolic blood pressure to no less than $100 \mathrm{mmHg}$.

3. Start digoxin, especially if atrial fibrillation is present.

4. Start $\beta$-blockers, such as carvedilol, metoprolol or bisoprolol. Begin with small doses and titrate up to the maximum tolerated dose. Use with caution in prepartum patients.

5. Consider the use of small dose spironolactone (e.g. $12.5 \mathrm{mg}$ od).

6. Consider the use of amlodipine.

7. Dietary consultation for fluid-restricted, low-salt diet.

8. Detailed patient education and counseling.

9. Referral to an exercise rehabilitation programme, if appropriate.

10. Vigilant and frequent follow-up, especially during the prepartum period.
Invasive haemodynamic monitoring is used if available to guide the acute phase of illness and therapy. The haemodynamic goals would be to achieve and maintain a mean arterial pressure of approximately $75 \mathrm{mmHg}$, and heart rate between 60 to 80 beats per minute, systemic vascular resistance between 800 and I,200 dynes/sec/cm, pulmonary capillary wedge pressure between 16 to $20 \mathrm{mmHg}$, and cardiac index of more than $2.5 \mathrm{~L} / \mathrm{min} / \mathrm{m}^{2}$.

\section{Other forms of treatment to be considered}

\section{Anticoagulation}

From natural history studies, there is a high incidence of thromboembolism in this population. Thrombi are the result of hypercoagulable state of pregnancy and of stasis and turbulent flow in dilated heart. Mortality due to embolic phenomena has been reported to be as high as $30 \%$. Therefore, anticoagulation with heparin (either unfractionated or low molecular weight heparin) or warfarin is advised.

\section{Immunosuppressive therapy}

Midei et al (9) studied I 4 patients with PPCM who had biopsy-proven myocarditis. Nine out of 10 patients who received immunosuppressive therapy (prednisolone and azathioprine) had symptomatic improvement, but so too were the other four patients who were not given immunosuppression (32). One retrospective study suggested that women with PPCM treated with intravenous immune globulin had a greater improvement in ejection fraction during early follow-up than patients treated conventionally (33). More recently, it was shown that the addition of pentoxifylline, a drug known to inhibit the production of TNF-alpha, to conventional treatment, improves outcome in patients with PPCM (34).

\section{Cardiac transplantation}

Women who fail maximal medical management may be candidates for cardiac transplantation. One study of I0 PPCM patients who underwent cardiac transplantation reported survival comparable to agematched women undergoing heart transplantation for other indications, but noted a marginally higher rate of biopsy-proven early rejection, necessitating increased cytolytic therapy (35).

\section{Prognosis}

Reported mortality of PPCM ranges from 25 to $50 \%$. Approximately $50 \%$ of patients show full recovery by six months after delivery. 10 to $20 \%$ will deteriorate despite treatment and die. Another 30 to $40 \%$ of patients will have partial or no recovery. 
The prognosis for women with PPCM appears to depend on the normalisation of left ventricular size and function within six months after delivery. In one study, approximately half of the 27 women studied had persistent left ventricular dysfunction. In this group, the cardiac mortality rate was $85 \%$ over five years, compared with the group in whom cardiac size returned to normal, who experienced no reported cardiac mortality in the same time interval (I). A more recent study corroborates these results: $50 \%(7 / / 4)$ of patients had dramatic improvement soon after delivery, but six of the seven remaining patients died (36). Survivors were found to have a higher mean ejection fraction $(23 \%$ vs. II\%) and smaller mean left ventricular cavity size $(5.8 \mathrm{~cm}$ vs. $6.9 \mathrm{~cm})$ at diagnosis. Other good prognostic indicators are normal pulmonary artery pressure, younger age, delay in diagnosis and low parity (37). The presence or absence of myocarditis is thought not to influence prognosis (38).

The effect on the foetus of PPCM patients has been reported in a study where there was an increase incidence of premature and low birth weight infants. There was, however, no foetal death (I5).

\section{Future Obstetric Recommendations}

Currently, there is no consensus regarding recommendations for future pregnancy after PPCM. Patients whose left ventricular size or function does not return to normal should be counseled strongly against subsequent pregnancy $(\mathrm{I})$ and treated accordingly, including adopting a heart-healthy diet and lifestyle.

Patients whose cardiomyopathy apparently resolves completely are a more difficult group to counsel. In the long-term follow-up study, eight out of 14 patients whose heart size returned to normal after the first episode of PPCM had subsequent pregnancies. Of the eight patients, two developed PPCM with subsequent pregnancies (I). Others (39) reported normal subsequent pregnancies and normal left ventricular function (by echocardiography) in four women whose heart size returned to normal after PPCM in a prior pregnancy. As PPCM has been associated with multiparity in some studies, the risk of irreversible cardiac damage may increase with each subsequent pregnancy. In addition, even though the left ventricular size and function return to normal, there is evidence that contractile reserve is impaired (40) and recurrence of PPCM despite rapid return of heart size and function to normal in the prior affected pregnancy has been reported (4I). Therefore, subsequent pregnancies, if they cannot be avoided, should be managed in collaboration with a high-risk perinatal centre.

\section{References}

I. Demakis JG, Rahimtoola SLI, Sutton, GC et al. Natural course of peripartum cardiomyopathy. Circulation 197I; 44:1058-6I.

2. Seftel $H$, Susser M. Maternity and myocardial failure in African women. Br Heart J 196I; 28:157-67.

3. Manolio TA, Baughman KL, Rodeheffer R, et al. Prevalence and etiology of idiopathic cardiomyopathy (summary of a National Heart, Lung, and Blood Institute Workshop). Am J Cardiol. 1992; 69:|458-| 466.

4. Ventura SJ, Peters KD, Martin JA, et al. Births and deaths: United States, 1996. Mon Vital Stat Rep. 1997; 46(I suppl 2): $1-40$.

5. Familial occurrence of postpartal heart failure. Arch Intern Med. 1962; III:163-166.

6. Massad LS, Reiss CK, Mutch DG, et al. Family peripartum cardiomyopathy after molar pregnancy. Obstet Gynecol. 1993; 81:886-888.

7. Pearl W. Familial occurrence of peripartum cardiomyopathy. Am Heart J. 1995; 129:421-422.

8. Melvin KR, Richardson PJ, Olsen EG, et al. Peripartum cardiomyopathy due to myocarditis. N Engl J Med. 1982; 307:731-734.

9. Midei MG, DeMent SH, Feldman AM, et al. Peripartum myocarditis and cardiomyopathy. Circulation. 1990; 81: 922-928.

10. Farber PA, Glasgow LA. Viral myocarditis during pregnancy: encephalomyocarditis virus infection in mice. Am Heart J. 1970; 80:96-102.

II. Artlett CM, Jimenez SA, Smith JB. Identification of fetal DNA and cells in skin lesions from women with systemic sclerosis. N Engl J Med. 1998; 338:1 I86-II91.

12. Nelson JL, Bianchi DW, Ober C, et al. Microchimerism and HLA compatible relationships of pregnancy in scleroderma. Lancet. 1998; 351:559-562.

13. Geva T, Mauer MB, Striker L, et al. Effects of physiologic load of pregnancy on left ventricular contractility and remodeling. Am Heart J. 1997; 133:53-59.

14. Mone SM, Sanders SP, Colan SD. Control mechanisms for physiological hypertrophy of pregnancy. Circulation. 1996; 94:667-672.

15. Witlin AG, Mable WC, Sibai BM. Peripartum cardiomyopathy: An ominous diagnosis. Am J Obstet Gynecol. 1997; 176:182-188.

16. Sliwa K, Skudicky D, Bergemann A, et al. Peripartum cardiomyopathy: analysis of clinical outcome, left ventricular function, plasma levels of cytokines and Fas/APOI. J Am Coll Cardiol. 2000; 35(3):70I-705.

17. Coulson CC, Thorp JM Jr, Mayer DC, et al. Central haemodynamic effects of recombinant human relaxin in the isolated, perfused rat heart model. Obstet Gynecol. 1996; 87:610-612. 
18. Brito O, de Lacerda AP, Freitas P, et al. Incessant atrial tachycardia and peripartum cardiomyopathy - a therapeutic challenge. Rev Port Cardiol. 1997; I6(2): I57-I63.

19. Janssens U, Klues HG, Hanrath P. Successful thrombolysis of right atrial and ventricle thrombi in a patient with peripartum cardiomyopathy and extensive thromboembolism. Heart. 1997; 78(5):515-516.

20. Melndoe AK, Hammond EJ, Babington PC. Peripartum cardiomyopathy presenting as a cardiac arrest at induction of anaesthesia for emergency Caesarian section. Br J Anaesth. 1995; 75(I):97-10I.

21. O'Connel JB, Costanzo-Nordin MR, Subramaniam R, et al. Peripartum cardiomyopathy: Clinical, haemodynamic, histologic and prognostic characteristics. J Am Coll Cardiol. 1986; 8:52-56.

22. Van Haevan KH, Kitsis RN, Katz SD. Peripartum versus idiopathic dilated cardiomyopathy in young women - a comparison of clinical, pathological and prognostic features. Int J Cardiol. 1993; 40:57.

23. CONSENSUS Trial Study Group. Effects of Enalapril on mortality in severe congestive cardiac failure. $N$ Engl J Med. 1987; 316:1429-1435.

24. Pitt B, Poole-Wilson PA, Segal R, et al. Effect of losartan compared with captopril on mortality in patients with symptomatic heart failure: Randomized trial - the losartan heart failure survival study (ELITE II). Lancet. 2000; 355(92I5): I582-I587.

25. Cohn JN, Tognoni G, Valsartan Heart Failure Trial (Val-HeFT) Investigators. A randomized trial of the angiotensin-receptor blocker valsartan in chronic heart failure. N Engl J Med. 200 I; 345(23): I667-I675.

26. Cohn JN, Johnson G, Ziesche S, et al. A comparison of enalapril with hydraline and isosorbide dinitrate in the treatment of chronic congestive heart failure. $\mathrm{N}$ Engl J Med. 1991; 325:303-310.

27. Packer M, Gheorghia de M, Young JB, et al.Withdrawal of digoxin from patients with chronic heart failure treated with angiotensin-converting enzyme inhibitors. $N$ Engl J Med. 1993; 329:1-7.

28. CIBIS Investigators and Committees. A randomized trial of beta-blockade in heart failure: The Cardiac Insufficiency Bisoprolol Study (CIBIS). Circulation. 1994; 90: I765-1773.

29. MERIT-HF Study Group. Effect of Metoprolol CR/XL in chronic heart failure: Metoprolol CR/XL Randomized Intervention Trial in Congestive Heart Failure (MERITHF). Lancet. 1999; 353:200I-2007.
30. Packer M, Coats AJ, Fowler MB, COPERNICUS Study Group. Effect of carvedilol on survival in severe chronic heart failure. N Engl J Med. 200 I; 344(22): I65 I-I 658.

3I. Packer M, O'Connor CM, Ghali JK, et al for the PRAISE Study Group. Effect of amlodipine on morbidity and mortality in severe chronic heart failure. $\mathrm{N}$ Engl J Med. 1996; 335:1107-1114.

32. Midei MG, Dement SH, Feldmon AM, et al. Peripartum myocarditis and cardiomyopathy. Circulation. 1990; 81:922-928.

33. Bozkurt B, Villaneuva FS, Holubkov R, et al. Intravenous immune globulin in the therapy of peripartum cardiomyopathy. J Am Coll Cardiol. 1999; 34: I77-180.

34. Sliwa K, Skudicky D, Candy G, et al. The addition of pentoxifylline to conventional therapy improves outcome in patients with peripartum cardiomyopathy. Eur J Heart Fail. 2002; 4(3):305-309.

35. Keogh A, Macdonald P, Spratt P, et al. Outcome in peripartum cardiomyopathy after heart transplantation. J Heart Lung Transplant. 1994; 13:202-207.

36. Sutton MS, Cole P, Plappert M, et al. Effects of subsequent pregnancy on left ventricular function in peripartum cardiomyopathy. Am Heart J. 1991; 121:1776-1778.

37. Carvalho A, Brandao A, Martinez EE, et al. Prognosis is peripartum cardiomyopathy. Am J Cardiol. 1989; 64: 540-542.

38. Felker GM, Jaeger CJ, Klodas E, et al. Myocarditis and long-term survival in peripartum cardiomyopathy. Am Heart J. 2000 Nov; I 40(5):785-9I.

39. Sutton MS, Cole P, Plappert M, et al. Effects of subsequent pregnancy on left ventricular function in peripartum cardiomyopathy. Am Heart J. 199I; 121: 1776- 1778.

40. Lampert M, Weinert L, Hibbard J, et al. Contractile reserve in patients with peripartum cardiomyopathy and recovered left ventricular function. Am J Obstet Gynecol. 1997; 176(I pt I):189-195.

41. Ceci O, Berardesca C, Caradonna F, et al. Recurrent peripartum cardiomyopathy. Eur J Obstet Gynecol Reprod Biol. 1998; 76:29-30. 